\title{
Long-term effectiveness of pulmonary rehabilitation in patients with chronic airway obstruction
}

\author{
K. Foglio, L. Bianchi, G. Bruletti, L. Battista, M. Pagani, N. Ambrosino
}

Long-term effectiveness of pulmonary rehabilitation in patients with chronic airway obstruction. K. Foglio, L. Bianchi, G. Bruletti, L. Battista, M. Pagani, N. Ambrosino. (C)ERS Journals Ltd 1999.

ABSTRACT: The aim of this study was to evaluate the long-term outcome of an outpatient pulmonary rehabilitation programme (PRP) in patients with chronic airway obstruction (CAO).

In 61 CAO patients (35 asthmatics and 26 chronic obstructive pulmonary disease (COPD)) lung and respiratory muscle function, exercise tolerance (by symptom limited cycloergometer and walking tests), dyspnoea (Borg scale, visual analogue scale (VAS), baseline and transitional dyspnoea index (BDI and TDI, respectively)) and quality of life (St George's Respiratory Questionnaire (SGRQ)) were assessed at baseline (to), at discharge (t1) and 12 months postdischarge (t2). Preprogramme and postprogramme hospital admissions and exacerbations of disease were also recorded.

In comparison with baseline, no significant change was observed in lung function tests in either diagnostic group, either at $t 1$ or at $t 2$. In both groups improvements in respiratory muscle strength, exercise tolerance, Borg scale and VAS reported at $t 1$ were partially reduced at $t$. Analysis of variance showed that these changes over time were similar in the two groups. Mean values of SGRQ and BDI/TDI improved at $t$, and, unlike exercise tolerance, did not worsen at $t 2$. However, a clinically relevant difference in SGRQ between $t 2$ and $t 0$ was reported only in $56 \%$ of asthmatics and $52 \%$ of COPD patients. Compared with the preceding $2 \mathrm{yrs}$, in the year following PRP, hospital admissions and disease exacerbations decreased significantly in both diagnostic groups.

Regardless of diagnosis, patients with chronic airway obstruction who underwent an outpatient pulmonary rehabilitation programme maintained an improved quality of life 12 months postdischarge despite a partial loss of the improvement in exercise tolerance.

Eur Respir J 1999; 13: 125-132.

The main conditions associated with chronic airway obstruction (CAO) are chronic bronchitis and emphysema. Despite having distinct pathophysiological features, chronic asthma with incomplete remission of airway obstruction has been included as a subset of CAO. It is often not possible to differentiate asthmatics from patients with chronic bronchitis and emphysema who have partly reversible airway obstruction [1].

Rehabilitation for patients with chronic lung diseases is well established and widely accepted as a means of enhancing standard therapy in order to alleviate symptoms and optimize function [2-5]. Most studies on pulmonary rehabilitation have relied on hospital-based and outpatient programmes, although a recent European trial confirmed that pulmonary rehabilitation programmes (PRP) can also be successfully implemented at home [6]. The short-term benefits of pulmonary rehabilitation on exercise tolerance in patients with chronic obstructive pulmonary disease (COPD) have been well documented [7], but only a few investigators have examined the long-term effects of these gains on health-related quality of life. GUYATT et al. [8], evaluating 4-6-week PRP in inpatients followed-up for 2830 weeks, and VALE et al. [9], evaluating 6-week PRP in
Salvatore Maugeri Foundation IRCCS, Lung Function and Pulmonary Rehabilitation Unit, and Medical Psychology Unit, Medical Centre of Gussago, Italy.

Correspondence: N. Ambrosino

Lung Function Unit

Fondazione "S. Maugeri" Centro Medico di Gussago

Via Pinidolo 23

25064 Gussago (BS)

Italy

Fax: 39302521718

Keywords: Bronchial asthma

chronic obstructive pulmonary disease dyspnoea

exercise tolerance

quality of life

Received: February 261998

Accepted after revision August 311998 outpatients followed-up for 3-21 months, found an initial improvement followed by a partial reduction in quality of life months later. More recently, KeTELAARS et al. [10] defined COPD patients in whom long-term benefits of an inpatient PRP were sustained 9 months postdischarge, reporting that these patients required differentiated aftercare programmes of postdischarge pulmonary rehabilitation.

Although beneficial effects have been reported in patients with disease other than COPD [11], few data are available on the effects of PRP in asthmatic patients [1214]. Even less is known on the long-term effects of such programmes in these patients [15]. The aim of this study was, therefore, to evaluate the one-year outcome of a dayhospital-based outpatient PRP in CAO patients (COPD and asthmatics) by assessing exercise tolerance, dyspnoea and quality of life.

\section{Patients and methods}

Patients gave their informed consent to participate in the study, which was approved by the Ethical Committee of Salvatore Maugeri Foundation and was conducted according to the Declaration of Helsinki. 


\section{Patients}

Seventy-one consecutive CAO patients in a stable condition (32 COPD and 39 asthmatics) admitted to a dayhospital-based PRP entered the study. The diagnosis of COPD was made according to the American Thoracic Society (ATS) guidelines [16]. COPD patients had a history of smoking ( $>20$ pack-yrs) but had to be (and actually were) exsmokers. Asthma was characterized by dyspnoea with wheezing, variable airflow limitation with reversible obstruction (range 12-55\%; mean \pm SD $28 \pm 10 \%$ ) and bronchial hyperresponsiveness [17] in the absence of smoking history. At the time when they were recruited for this study, all patients were in a stable condition, as assessed by stability in blood gas values, and were free from exacerbation in the 4 weeks before their entry in the study. Patients with other organ failure, cancer or inability to co-operate were excluded from the study. All asthmatic patients received inhaled steroids and bronchodilators, whereas all COPD patients received regular treatment with inhaled bronchodilators. No COPD patients received regular treatment with inhaled or oral steroids. Both COPD patients and asthmatics had received systemic steroids during exacerbations of their diseases. No change in the routine therapy was made in the week preceding the inclusion into the study. During follow-up patients were asked about changes in therapy. Care was taken that the 12-month follow-up visit and assessment were performed when the patients were in a stable state and at least 2 weeks from exacerbations. The patients' characteristics according to their diagnosis are shown in table 1.

\section{Rehabilitation programme}

Patients were referred to the centre by their general practitioners (GP) or respiratory physician. The programme included optimization of the pharmacological treatment and three 3-h sessions per week for 8-10 weeks, including: 1) supervised incremental exercise until achieving 30min continuous cycling at $50-70 \%$ of the maximal load

Table 1. - Demographic, anthropometric and functional characteristics of the study patients

\begin{tabular}{lcc}
\hline & Asthmatic & COPD \\
\hline $\mathrm{n}$ & 35 & 26 \\
$\mathrm{Sex} \mathrm{M} / \mathrm{F}$ & $16 / 19$ & $23 / 3$ \\
Age yrs & $56 \pm 10$ & $62 \pm 8^{*}$ \\
Weight kg & $71 \pm 14$ & $72 \pm 10$ \\
$\%$ IBW & $110 \pm 11$ & $104 \pm 10$ \\
$\mathrm{FVC} \%$ pred & $88 \pm 20$ & $65 \pm 15^{*}$ \\
$\mathrm{FEV} 1 \%$ pred & $64 \pm 16$ & $43 \pm 15^{*}$ \\
$\mathrm{FEV} 1 / \mathrm{VC} \%$ & $52 \pm 9$ & $41 \pm 13^{*}$ \\
$\mathrm{TGV} \%$ pred & $122 \pm 23$ & $142 \pm 36^{*}$ \\
$\mathrm{~Pa}_{\mathrm{a}} \mathrm{O}_{2} \mathrm{kPa}$ & $10.2 \pm 1.3$ & $10.1 \pm 1.3$ \\
$\mathrm{~Pa}, \mathrm{CO}_{2} \mathrm{kPa}$ & $4.9 \pm 0.6$ & $5.3 \pm 0.5^{*}$ \\
$\mathrm{pH}$ & $7.41 \pm 0.02$ & $7.40 \pm 0.02$ \\
\hline $\mathrm{Da}$ & &
\end{tabular}

Data are mean \pm SD. COPD: chronic obstructive pulmonary disease; M: male; F: female; IBW: ideal body weight; FVC: prebronchodilator forced vital capacity; FEV1: prebronchodilator forced expiratory volume in one second; VC: vital capacity; TGV: prebronchodilator thoracic gas volume; $\mathrm{Pa}_{\mathrm{a}} \mathrm{O}_{2}$ : arterial oxygen tension; $\mathrm{Pa}_{\mathrm{a}} \mathrm{CO}_{2}$ : arterial carbon dioxide tension. *: $\mathrm{p}<0.05$. achieved on an incremental cycloergometer exercise test carried out at admission (the criteria used to increase or decrease the intensity and/or duration of the training session were those of MALTAIs et al. [18]); 2) abdominal, upper and lower limb muscle activities lifting progressively increasing light weights $(300-500 \mathrm{~g})$, shoulder and full arm circling and other exercises according to CLARK et al. [19]; 3) patient and family education with the education sessions diagnosis specific (e.g. COPD patients focused on continuing to abstain from smoking and asthmatics on environmental control, the importance of inhaled steroids and management plans); and 4) nutritional programmes and psychosocial counselling, when appropriate with nutritional programmes (all hypocaloric diets) performed in four asthmatics and two COPD patients. Three asthmatics and two COPD patients received one session per week of psychosocial counselling. Care was offered by a multidisciplinary team consisting of chest physicians, nurses, physical therapists, a dietician and a psychologist. If desired, patients could rest in dedicated beds and had meals in the hospital facilities. After discharge from the programme, the patients were encouraged to perform daily life activities but neither structured exercise programmes nor periodical hospital visits were prescribed. The only followup visits were made at 6 and 12 months postdischarge, when physiological evaluation was performed.

\section{Measurements}

The following measurements were performed on 2 consecutive days, at baseline (t0), at discharge (t1) and 12 months postdischarge $(t 2)$.

Lung volumes and forced vital capacity (FVC) were measured by means of a constant-volume body plethysmograph (Medical Graphic Corp., St Paul, MN, USA). The predicted values according to QUANJER [20] were used. Arterial blood was sampled at the radial artery while the patients breathed room air for at least $1 \mathrm{~h}$ in the sitting position. Arterial oxygen tension $\left(\mathrm{Pa}, \mathrm{O}_{2}\right)$, arterial carbon dioxide tension $\left(\mathrm{Pa}_{\mathrm{a}} \mathrm{CO}_{2}\right)$ and $\mathrm{pH}$ were measured by means of an automated analyser (ABL 300; Radiometer, Copenhagen, Denmark). The respiratory muscle strength was assessed by measuring maximal inspiratory pressure (MIP) at the level of functional residual capacity (FRC) and maximal expiratory pressure (MEP) at the level of total lung capacity (TLC), respectively, according to the method of BLACK and HyATT [21] using a respiratory module system (Medical Graphic Corp.). The predicted values according to BRUSCHI et al. [22] were used. Symptom limited incremental exercise tests were performed on an electrically braked cycloergometer (Ergometris 800S; Sensormedics, Yorba Linda, CA, USA) using the standard 1-min incremental cycle exercise protocol. Functional and metabolic data were determined at rest and during exercise by means of a computerized system (2900Z; Sensormedics). Mixedexpired gas data, minute ventilation and breathing pattern, oxygen consumption $\left(V^{\prime} \mathrm{O}_{2}\right), \mathrm{CO}_{2}$ production and respiratory exchange ratio were monitored continuously as average values of 20 -s intervals. Electrocardiographic activity was monitored continuously and systemic arterial blood pressure was registered every $3 \mathrm{~min}$ using a sphigmomanometer. After stabilization and a 2-min period of unloaded pedalling at 60 cycles $\cdot \mathrm{min}^{-1}$ the load was increased by 
$10 \mathrm{~W}$ each minute. The patients were strongly encouraged to cycle to the point of intolerable breathlessness, discomfort or exhaustion, until the maximal cardiac frequency was achieved or an abnormal electrocardiogram was noted (symptom-limited exercise test) or whenever the patient wanted to stop. At rest and at $10 \mathrm{~W}$ intervals, patients were asked their perceived breathlessness by pointing to a number or phrase on a 10-point modified Borg scale set in large type on a sheet in front of them [23]. Exercise capacity was evaluated also by means of the 6-minute walking distance test (6MWD) [24]. Verbal encouragement was given at definite intervals during the test. Three practice tests were performed on 2 consecutive days and the highest value was recorded. All measurements were performed and recorded under the supervision of a nurse not involved in the study.

The baseline dyspnoea index (BDI) assessed chronic exertion dyspnoea at $t 0$ and $t 2$. BDI is a multidimensional instrument for measuring dyspnoea based on three components that evoke dyspnoea: magnitude of task, magnitude of effort and functional impairment [25]. Each component scores from 0 (severe impairment) to 4 (not impaired). A baseline focal score obtained as the sum of the three components ranged $0-12$; the lower the rating the worse the dyspnoea. The transitional dyspnoea index (TDI) was used at $t 1$ to evaluate differences in dyspnoea from baseline $(t 0)$ and at $t 2$ to evaluate differences from $t 1$. TDI provides specific criteria for each of the three components to measure change from the baseline state. Change in each component scores from -3 (major deterioration) to +3 (major improvement); a TDI focal score is obtained by adding scores for each of the three components (range -9$+9)$. Italian translations of BDI and TDI were administered $[25,26]$. Subjective rating of dyspnoea was scored using a visual analogue scale (VAS) [25].

The health-related quality of life was evaluated by means of the St George's Respiratory Questionnaire (SGRQ). The SGRQ has been validated both for COPD and asthma and, therefore, is a logical outcome measure of health-related quality of life for this study [27]. The SGRQ consists of 76 items and measures three components: the first section, Symptoms, contains items concerned with the level of symptomatology; the second section, Activity, is concerned with physical activities that either cause or are limited by breathlessness; and the final section is Impact and covers such factors as employment, being in control of health, panic, stigmatization, the need for medication, expectations for health and disturbances to daily life [27]. The three components of SGRQ are scored separately in the range $0-100 \%$, with a score of 0 indicating no impairment, and a total score is computed. The SGRQ scores are calculated using weights attached to each item in the questionnaire. A difference $>4$ points in total SGRQ in the individual patient was considered clinically relevant (improvers) [27]. Italian translations of the SGRQ were administered [28].

Hospital admissions were recorded, along with the number of exacerbations requiring change of usual medication and prescription of systemic steroids and/or antibiotics by the GP or respiratory physician in the last 2 yrs (followback). These data were obtained by asking the patients at admission, from the hospital registers and interviewing relatives or the GP. Postdischarge, patients were asked to complete a record of hospital admissions and exacerba- tions over the following year. Data were also collected from hospital registers, interviewing relatives or the GP. Finally, the mortality rate was recorded in the follow-up in both groups.

\section{Statistical analyses}

Results are expressed as mean \pm SD or SEM when specified. All analyses were performed using specific software (BMDP PC 90; Statistical Software, Los Angeles, CA, USA). Differences between groups (asthmatics versus COPD and improvers versus nonimprovers) and within groups (time course) were evaluated by multivariate or univariate analysis of variance (ANOVA) for repeated measure options. Differences between paired or unpaired groups of data were evaluated by a t-test with Bonferroni adjustment and were applied as required by ANOVA interaction. Chi-squared analysis was performed to evaluate the relationship between hospital admissions and clinically relevant improvement in quality of life at $1 \mathrm{yr}$. A p-value $<0.05$ was considered significant.

\section{Results}

Complete data sets were obtained from 61 (35 asthmatics, 26 COPD) out of $71 \mathrm{CAO}$ patients. Six patients were lost at follow-up and four patients were excluded from the study owing to intervening physiological (one asthmatic patient became pregnant) or pathological conditions (one renal cancer, one stroke, one orthopaedic problem). These subjects did not differ in any functional characteristics. Anthropometric, demographic and functional data of the patients according to diagnosis are shown in table 1 . Compared with asthmatics, COPD patients were older and suffered from more severe obstruction (forced expiratory volume in one second (FEV1)) and hyperinflation (thoracic gas volume (TGV)) and showed a greater reduction in exercise tolerance, as assessed by the cycloergometer but not by the walking test (table 2).

At $1 \mathrm{yr}$ postdischarge no patients in either group had died. ANOVA showed that changes over time of outcome measurements were similar in asthmatics and COPD patients. Henceforth, in this section results will be depicted in tables according to diagnosis but will be described for the whole group of patients independent of diagnosis. In comparison with baseline, no significant change was observed in lung function tests in either diagnostic group, either at discharge or at $1 \mathrm{yr}$ follow-up.

The time course of respiratory muscle function and exercise tolerance of patients according to diagnosis is shown in table 2. At $t 1$ both MIP and MEP showed a slight but significant increase, which was partially lost at $t 2$, with values of MIP still remaining higher than at to. Exercise tolerance showed the same trend as respiratory muscle function (table 2).

The time course of breathlessness is shown in table 3 . Dyspnoea, as assessed by VAS and by Borg scale at isowatt, improved after the PRP, but again the benefit was lost at 1 yr. TDI improved in the comparison $t 1$ versus to and remained unchanged or slightly worsened in the comparison $t 2$ versus $t 1$. 
Table 2. - Time course of respiratory muscle function and exercise performance

\begin{tabular}{|c|c|c|c|c|c|c|}
\hline & \multicolumn{3}{|c|}{ Asthmatics } & \multicolumn{3}{|c|}{ COPD } \\
\hline & to & $t 1$ & $t 2$ & to & $t 1$ & $t 2$ \\
\hline MIP \% pred & $65 \pm 18$ & $77 \pm 21^{*}$ & $75 \pm 23 *$ & $62 \pm 21$ & $71 \pm 18^{*}$ & $63 \pm 20^{\dagger}$ \\
\hline MEP \% pred & $69 \pm 18$ & $78 \pm 19^{*}$ & $73 \pm 21^{\dagger}$ & $77 \pm 26$ & $87 \pm 22 *$ & $80 \pm 20^{\dagger}$ \\
\hline 6MWD m & $471 \pm 61$ & $508 \pm 56^{*}$ & $485 \pm 60 * \dagger$ & $469 \pm 62$ & $507 \pm 72 *$ & $481 \pm 74 * i$ \\
\hline$V^{\prime} \mathrm{O}_{2}$, peak $\mathrm{mL} \cdot \mathrm{kg}^{-1} \cdot \mathrm{min}^{-1}$ & $21 \pm 5$ & $24 \pm 7 *$ & $20 \pm 6^{\dagger}$ & $15 \pm 2$ & $18 \pm 3 *$ & $16 \pm 5^{\dagger}$ \\
\hline Maximal load W & $85 \pm 26$ & $103 \pm 29 *$ & $90 \pm 23^{\dagger}$ & $75 \pm 17$ & $91 \pm 22 *$ & $78 \pm 20^{\dagger}$ \\
\hline
\end{tabular}

Data are mean \pm SD. COPD: chronic obstructive pulmonary disease; $t 0$ : baseline; $t 1$ : discharge; $t 2: 12$ months postdischarge; MIP: maximal inspiratory pressure; MEP: maximal expiratory pressure; 6MWD: six-minute walking distance; $V$ ' $\mathrm{O}_{2}$,peak: peak oxygen consumption. *: $\mathrm{p}<0.05$ versus baseline; ${ }^{\dagger}: \mathrm{p}<0.05$ versus $t 2$ discharge.

The time course of quality of life as assessed by SGRQ (total and component scores) is also shown in table 3. Total SGRQ score improved after PRP and, unlike exercise tolerance and dyspnoea, the benefits of which were reduced when assessed after $1 \mathrm{yr}$, it did not worsen in comparison to $t 1$. The three components of SGRQ showed different behaviour. In comparison to $t 0$, symptoms did not improve at $t 1$, but showed a significant improvement at $t 2$, whereas Activity and Impact did improve at discharge, remaining unchanged at $t 2$ (table 3 ). As a result the quality of life was better at $1 \mathrm{yr}$ than at baseline. Regression analysis showed that there was no significant relationship between $t 2-t 1$ change in quality of life and 6MWD ( $\mathrm{r}=0.17)$ (fig. 1).

Considering as clinically relevant an individual difference of 4 points in the total SGRQ score [27] between the assessments at $t 2$ and $t 0$, patients were divided into "improvers" and "nonimprovers". According to this division, $56 \%$ of asthmatics and $52 \%$ of COPD patients were considered "improvers". Baseline values of improvers and nonimprovers differed significantly only as for SGRQ (Total, Symptoms, Impact but not Activity) and BDI (table 4). As shown in figure 2, CAO patients whose improvement in SGRQ at $t 2$ was clinically relevant suffered from the worst quality of life at baseline and also showed an improvement in SGRQ at discharge. As clearly confirmed in figure 2, exercise tolerance as assessed by 6MWD at $t 2$ decreased in comparison to $t 1$, thus demonstrating a different behaviour from SGRQ.

Figure 3 shows the frequency distribution of hospital admissions of patients before and after the PRP according to the diagnosis underlying CAO. In comparison to the 2 yrs before PRP, in the year following PRP hospital admissions per patient significantly decreased in both groups (from $0.9 \pm 0.8$ and $0.9 \pm 0.7$ in the 2 yrs preceding, respectively, to $0.03 \pm 0.2$ at discharge and from $1.0 \pm 0.8$ and $0.8 \pm 0.7$ to $0.1 \pm 0.3$ in asthmatics and COPD, respectively; $\mathrm{p}=0.005$ ). A similar observation was made as for the exacerbations per year requiring systemic steroids (from $3.2 \pm 0.6$ to $0.9 \pm 0.7$ and from $3.2 \pm 0.8$ to $1.2 \pm 0.8$ in asthmatics and COPD, respectively). Chi-squared analysis showed that, in comparison to nonimprovers, improver asthmatics but not COPD patients suffered from a greater number of hospital admissions in the 2 yrs preceding PRP (in asthmatics: improvers $=60 \%$ with one or more admissions per year; nonimprovers $=18 \% ; \mathrm{p}=0.009$; in COPD: improvers $=47 \%$ with one or more admissions per year; nonimprovers $=38 \%$; $\mathrm{p}=0.24$ ).

\section{Discussion}

The main result of this study is that CAO patients may receive short- and long-term (1 yr) benefits from a hospitalbased outpatient pulmonary rehabilitation programme independent of their underlying diagnosis. This study confirms that pulmonary rehabilitation in an outpatient setting (on a day-hospital basis) results in short-term improvement in exercise tolerance, dyspnoea and quality of life in COPD patients. It is the first to report data on the long-term effects of pulmonary rehabilitation in asthmatic patients. Independent of the diagnosis, 12 months postdischarge CAO patients still maintained a good health-related quality of life, despite a partial loss of the postprogramme improvement in exercise tolerance.

The day-hospital-based programme was performed in outpatients and included exercise training, education and psychosocial support. It has been demonstrated that in

Table 3. - Time course of dyspnoea and quality of life

\begin{tabular}{|c|c|c|c|c|c|c|}
\hline & \multicolumn{3}{|c|}{ Asthmatics } & \multicolumn{3}{|c|}{ COPD } \\
\hline & $t 0$ & $t 1$ & $t 2$ & to & $t 1$ & $t 2$ \\
\hline VAS \% & $20 \pm 16$ & $14 \pm 13^{*}$ & $18 \pm 14^{\dagger}$ & $25 \pm 13$ & $15 \pm 11 *$ & $23 \pm 16^{\dagger}$ \\
\hline Borg isowatt & $5.7 \pm 1.5$ & $3.7 \pm 1.4^{*}$ & $4.5 \pm 1.8 * \dagger$ & $5.6 \pm 1.3$ & $3.6 \pm 0.9 *$ & $4.7 \pm 1.2 * \dagger$ \\
\hline BDI & $7.1 \pm 1.1$ & & $8.8 \pm 1.6$ & $6.8 \pm 1.7$ & & $7.7 \pm 1.3$ \\
\hline TDI & & $+5.7 \pm 2.3$ & $-0.7 \pm 1.2$ & & $+5.6 \pm 2.2$ & $-0.9 \pm 1.2$ \\
\hline \multicolumn{7}{|l|}{ SGRQ } \\
\hline Total & $41 \pm 15$ & $35 \pm 16^{+}$ & $29 \pm 16^{*}$ & $41 \pm 16$ & $35 \pm 15^{*}$ & $34 \pm 14^{*}$ \\
\hline Symptoms & $52 \pm 19$ & $52 \pm 18$ & $38 \pm 23 * \dagger$ & $44 \pm 21$ & $43 \pm 20$ & $38 \pm 24 * \dagger$ \\
\hline Activity & $55 \pm 17$ & $44 \pm 20^{\dagger}$ & $41 \pm 21^{*}$ & $55 \pm 20$ & $49 \pm 18 *$ & $48 \pm 14^{*}$ \\
\hline Impact & $29 \pm 17$ & $24 \pm 18^{\dagger}$ & $21 \pm 15^{*}$ & $31 \pm 19$ & $24 \pm 18^{*}$ & $25 \pm 14^{*}$ \\
\hline
\end{tabular}

Data are mean \pm SD. COPD: chronic obstructive pulmonary disease; $t 0$ : baseline; $t 1$ : discharge; $t 2: 12$ months postdischarge; VAS: visual analogue scale; BDI: baseline dyspnoea index; TDI: transitional dyspnoea index; SGRQ: St George's Respiratory Questionnaire. *: p< 0.05 versus baseline; ${ }^{\dagger}: \mathrm{p}<0.05$ versus discharge. Values of TDI refer to comparison of dyspnoea at $t 1$ versus $t 0$ and $t 2$ versus $t 1$, respectively. 


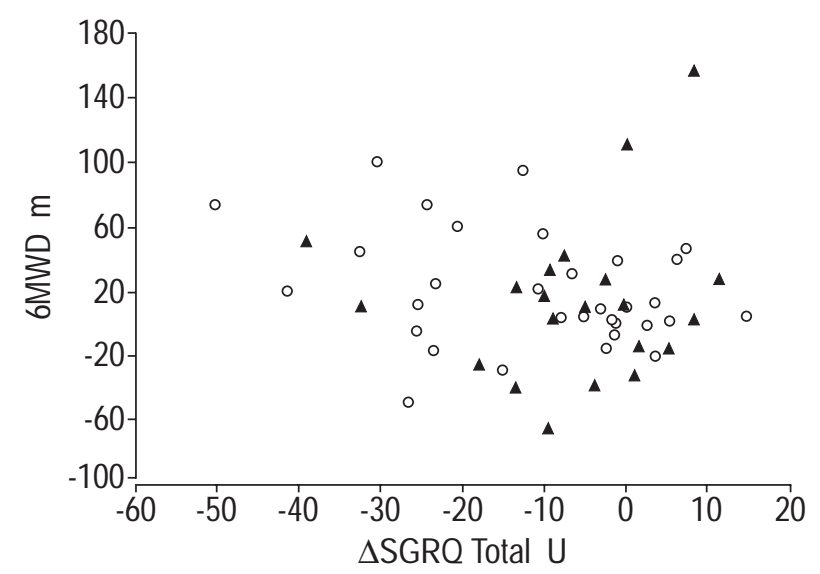

Fig. 1. - Scatterplot of changes between discharge ( $t 1)$ and 12 months postdischarge $(t 2)$ in six-minute walking distance (6MWD) and in quality of life (St George's Respiratory Questionnaire (SGRQ)) in asthmatics $(O)$ and patients with chronic obstructive pulmonary disease $(\mathbf{\Lambda})$. There was no significant relationship $(\mathrm{r}=0.17)$.

COPD patients respiratory rehabilitation is likely to improve exercise capacity and health-related quality of life if it includes exercise training. The relative contribution of education and psychological support has yet to be clearly established $[5,29]$. The lack of a control population (i.e. patients not performing the PRP or performing placebo manoeuvres) in this study may be criticized. However, the purpose of this study was not to assess the clinical usefulness of a PRP, which has been previously widely demonstrated in COPD patients [2-10]. Rather, the aim was to evaluate whether sustained long-term benefits could also be observed in asthmatics. Indeed, the long-term decay in exercise tolerance observed in these patients may exclude a motivation or a learning effect on the results.

Most of the patients reported in randomized, controlled trials of respiratory rehabilitation had severe COPD [4]. Benefits of high-intensity exercise training have been reported in asthmatic children [30], whereas a few studies have reported the short-term clinical and physiological effects of structured PRPs in adult asthmatics [12-14, 31, $32]$. To the best of the authors knowledge, this is the first study to report that the long-term results of such programmes in these patients are quite similar to those obtained

Table 4. - Differences in baseline values between improvers and nonimprovers

\begin{tabular}{lcc}
\hline & Improvers & Nonimprovers \\
\hline FEV1 \% pred & $56 \pm 20$ & $54 \pm 17$ \\
$\mathrm{~Pa}, \mathrm{O}_{2} \mathrm{kPa}$ & $10.2 \pm 1.3$ & $10.2 \pm 1.2$ \\
$\mathrm{~Pa}_{\mathrm{CO}} \mathrm{kpa}$ & $5.0 \pm 0.6$ & $5.0 \pm 0.5$ \\
6MWD m & $476 \pm 50$ & $469 \pm 63$ \\
SGRQ Total \% & $46 \pm 16$ & $34 \pm 13^{*}$ \\
SGRQ Symptoms & $56 \pm 18$ & $40 \pm 19^{*}$ \\
SGRQ Activity & $57 \pm 17$ & $53 \pm 18$ \\
SGRQ Impact & $37 \pm 19$ & $22 \pm 12^{*}$ \\
BDI & $6.7 \pm 1.3$ & $7.4 \pm 1.5^{*}$ \\
\hline
\end{tabular}

Data are mean \pm SD. FEV1: forced expiratory volume in one second; $\mathrm{Pa}, \mathrm{O}_{2}$ : arterial oxygen tension; $\mathrm{Pa}_{\mathrm{a}} \mathrm{CO}_{2}$ : arterial carbon dioxide tension; 6MWD: six-minute walking distance; SGRQ: St George's Respiratory Questionnaire; BDI: baseline dyspnoea index. *: $\mathrm{p}<0.05$.

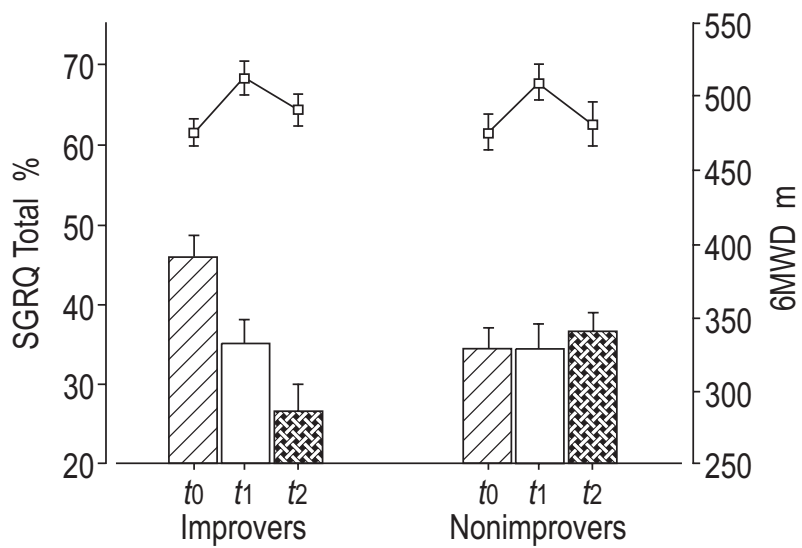

Fig. 2. - Time course (mean \pm SEM) of quality of life (St George's Respiratory Questionnaire (SGRQ) Total) (bars) and six-minute walking distance (6MWD) (squares and lines) in the whole group of patients with chronic airway obstruction according to the clinically relevant improvement in SGRQ at 12 months postdischarge $(t 2)$. Improvers suffered from a worse baseline ( $t 0)$ quality of life, improved at discharge $(t 1)$ and showed a further improvement at $t 2$. In both group of patients (improvers and nonimprovers) the increase in 6MWD observed at $t$ was not sustained at $t 2$.

in COPD patients. The programme included lower extremity exercise training, which has been recommended to be included in rehabilitation programmes for patients with COPD $[5,33]$. The patients also performed low-intensity upper extremity muscle conditioning [19] and the study did not aim to define which component resulted in the greatest benefit. CLARK et al. [19] reported improvements in wholebody endurance measured by treadmill walking, with a similar programme of peripheral muscle conditioning, although symptom-limited maximal $V^{\prime} \mathrm{O}_{2}$ was unchanged. The effects of specific (supported or unsupported) upper extremity exercise are still debated in COPD patients and have not been assessed in asthmatics. Therefore, the American College of Chest Physicians/American Association of Cardiovascular Pulmonary Rehabilitation statement [5] that "the exact form of [upper extremity] training that results in the best outcomes remains unknown" is justified. Although the present patients did not perform any specific respiratory muscle training, MIP and MEP were increased at discharge. Given the relative worsening of these measurements at 12 months postdischarge, a learning effect does not completely explain the postprogramme improvement in respiratory muscle function. Whether the low-intensity arm exercises influenced respiratory muscle function in these patients remains to be elucidated.

In this study breathlessness was assessed by a VAS, the Borg Scale, and the BDI and TDI. Concurrent validity has been established between VAS and the Borg scale. Both scales have been demonstrated to be sensitive to treatment effects and to be reproducible both in COPD and in asthmatics [25]. VAS is considered to be an appropriate tool to assess the acute or short-term efficacy of a particular medication or intervention on breathing difficulty induced by respiratory loads. The Borg scale is the major instrument used to quantify dyspnoea and other symptoms during an exercise test. BDI/TDI is an indirect measure of dyspnoea targeted to, or elicited by activities of daily living and provides different information from the VAS and the Borg scale. Indeed, in this study the long-term results of 

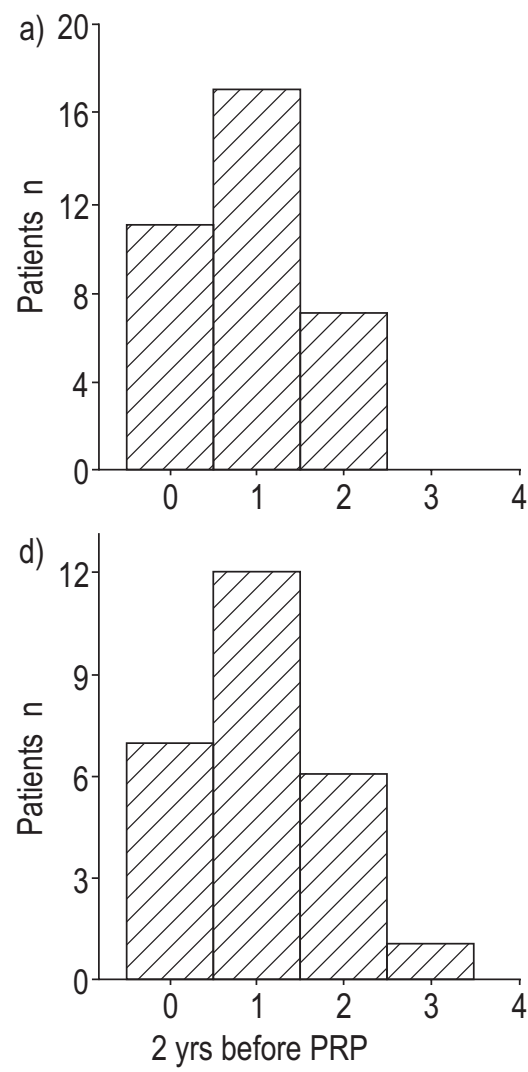

b) 18

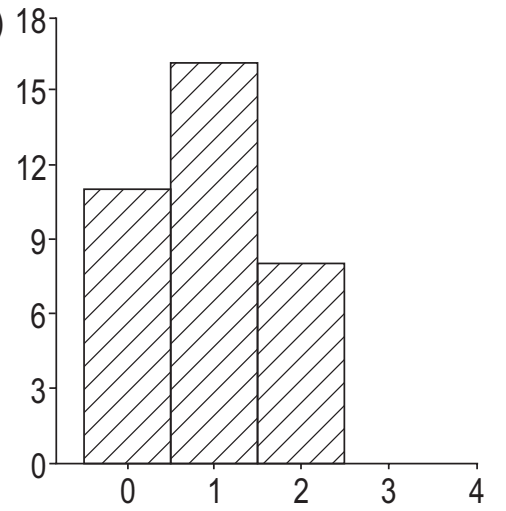

e) 15

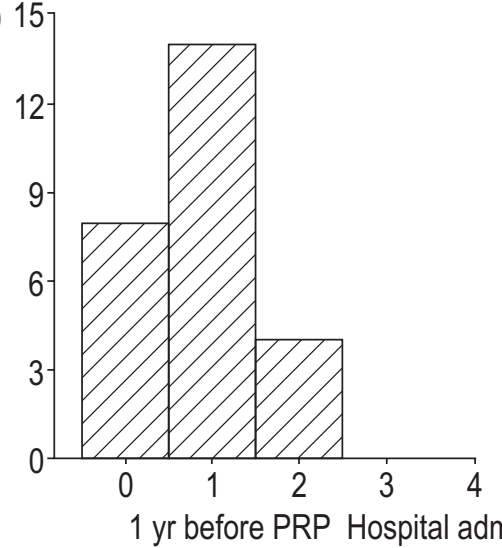

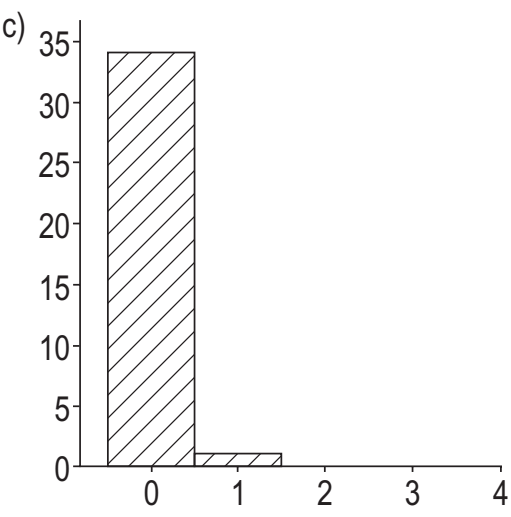

f)

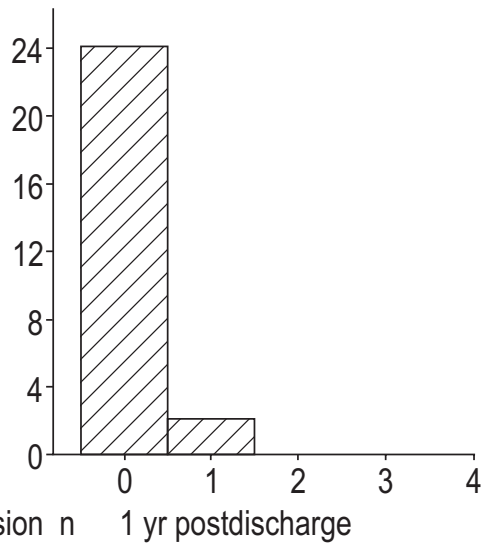

Fig. 3. - Frequency distribution of hospital admissions during the 2 yrs before and 1 yr after the pulmonary rehabilitation programme (PRP) in asthmatics $(a, b, c)$ and chronic obstructive pulmonary disease (d, e, f).

these measurements did not parallel BDI/TDI. The BDI has been reported to have the highest correlation with the walking distance, while a significant but lower correlation existed for lung function [25]. More recently, FERRARI et al. [26] showed a good relationship between BDI and indices of respiratory muscle effort.

The short- and long-term lack of changes in lung function after the PRP is not surprising and is consistent with previous reports $[2,4,5]$. The findings of the present study are in line with the observation that impairment of lung function weakly predicts dyspnoea and exercise tolerance in COPD [34], but extend those results in that the observation also applies to asthmatics.

In this study, COPD and asthmatic patients had similar SGRQ scores. It has been reported that quality of life is impaired in older asthmatics compared with controls [35]. Although other studies have shown that a PRP may lead to an improvement in quality of life of COPD patients $[5,6$, $8-10]$, the present study shows that these results may also be obtained in asthmatic patients. Different questionnaires have been used to assess quality of life as an outcome measure of PRP. The Chronic Respiratory Disease Questionnaire (CRQ) was used by WIJKSTRA et al. [6] to show that rehabilitation at home for 3 months followed by oncemonthly physiotherapy sessions improved the quality of life over 18 months. However, the change was not associated with a change in exercise tolerance. In the study by GUYATT et al. [8] 4-6-week inpatient PRP resulted in a significant improvement in physical and emotional func- tion and quality of life (as assessed by CRQ) 2 weeks after completion of the programme: 11 of 24 subjects $(46 \%)$ who showed initial improvement also showed improved quality of life at 6 months. The CRQ was also used by VALE et al. [9] to evaluate a 6-week outpatient PRP. A significant improvement in CRQ sum score followed the PRP; the CRQ sum declined at $11 \pm 6$ months after PRP, but remained significantly better than before rehabilitation. In the present study quality of life was assessed by the SGRQ [27]. This study confirms, the results of KETELAARs et al. [10] that not all patients may show a clinically significant improvement in quality of life after PRP, and extends these results to asthmatics. Studies in COPD patients using both the CRQ [36] and SGRQ [37] have shown that quality of life is only partially determined by lung function and exercise tolerance. Therefore, quality of life should be specifically measured in addition to physiological measures. The present study showed that sustained improvement in quality of life is unrelated to improvement in exercise tolerance. It confirms the results of REARDON et al. [38] in COPD patients, again extending those results to asthmatics. The finding that changes in the SGRQ do not follow changes in 6MWD probably reflects the comprehensive nature of pulmonary rehabilitation and the fact that healthrelated quality of life depends on more than exercise ability alone. The three components of SGRQ showed a different time course (table 3 ), confirming that they evaluate different aspects, which may be differently affected by a PRP. In particular, the Symptom score did not improve at the end of 
PRP in either group. This finding may be ascribed to the fact that the patients included in the study were in a stable state under optimal medical therapy. Rehabilitation improved both the Activity and the Impact.

It has been shown that in COPD, poor scores on the SGRQ are associated with more hospital admissions and use of resources, independent of physiological measures of disease severity [39]. The present study showed that hospital admissions were significantly reduced in the 12 months postdischarge compared with the 2 yrs before the PRP. The difference in accuracy of recording between follow-back and follow-up may have resulted in bias; however, any such bias would have underestimated the preprogramme events, and therefore, one can be quite confident that the improvement in hospital admissions is real. Which component of the programme most influenced this result is not clear. Most of the COPD patients had stopped smoking in the last 2 yrs before the PRP and this may have influenced the hospital admissions in the following year. The educational programme may have also resulted in better self-management of disease in the asthmatic patients [3]. Although the decrease in hospitalizations can be speculated upon and a control group would be needed, it has been demonstrated that in COPD patients the utilization of healthcare services is related to ventilatory and peripheral muscle force. Therefore, a direct effect of exercise conditioning cannot be ruled out [40]. Whether this observation also concerns asthmatic patients should be specifically studied. Whether the maintenance in good scores of quality of life are due to the reduced hospital admissions also needs to be better elucidated, although, at least in asthmatics, the results suggest a relationship.

The present rehabilitation programme was day-hospital based. GolDSTEIN et al. [2] performed their programme on an inpatient basis for 2 months and thereafter for another 4 months on an outpatient basis. Similar improvements were observed in that study compared with the outpatient programmes. In the study by САMBACH et al. [15] in COPD patients and asthmatics, as in the present study, similar improvements were observed in community-based as in outpatient hospital-based programmes. The present study confirms the usefulness of an outpatient-based rehabilitation programme.

In conclusion, a pulmonary rehabilitation programme based in a day hospital was able to improve exercise tolerance, dyspnoea and quality of life and to reduce hospital admissions in patients with chronic obstructive pulmonary disease and chronic bronchial asthma. Although the benefits in exercise tolerance were lost $1 \mathrm{yr}$ after the programme, more than half of the patients with chronic airway obstruction still reported improvements in their health-related quality of life.

\section{References}

1. Snider GL. Defining chronic obstructive pulmonary disease. In: Calverley P, Pride N, eds. Chronic Obstructive Pulmonary Disease. Cambridge, Chapman \& Hall Medical, 1995; pp. 1-8.

2. Goldstein RS, Gort EH, Stubbing D, Avendano MA, Guyatt GH. Randomised controlled trial of respiratory rehabilitation. Lancet 1994; 344: 1394-1397.

3. Ries Al, Kaplan RM, Limberg TM, Prewitt LM. Effects of pulmonary rehabilitation on physiologic and psychosocial outcomes in patients with chronic obstructive pulmonary disease. Ann Intern Med 1995; 122: 823-832.

4. Lacasse Y, Wong E, Guyatt GH, Cook DJ, Goldstein RS. Meta-analysis of respiratory rehabilitation in chronic obstructive pulmonary disease. Lancet 1996; 348: 11151119.

5. American College of Chest Physicians/American Associations of Cardiovascular Pulmonary Rehabilitation. Pulmonary rehabilitation. Joint ACCP/AACVPR evidence-based guidelines. Chest 1997; 112: 1363-1396.

6. Wijkstra PJ, Ten Vergert EM, Van Altena R, et al. Long term benefits of rehabilitation at home on quality of life and exercise tolerance in patients with chronic obstructive pulmonary disease. Thorax $1995 ; 50$ : 824-828.

7. Celli B. Pulmonary rehabilitation in patients with COPD. Am J Respir Crit Care Med 1995; 152: 861-864.

8. Guyatt GH, Berman LB, Townsend BA. Long-term outcome after respiratory rehabilitation. Can Med Assoc J 1987; 137: 1089-1095.

9. Vale F, Reardon JZ, ZuWallack RL. The long-term benefits of outpatient pulmonary rehabilitation on exercise end-urance and quality of life. Chest 1993; 103: 42-45.

10. Ketelaars CAJ, Huyer Abu-Saad H, Schlosser MAG, Mostert R, Wouters EFM. Long-term outcome of pulmonary rehabilitation in patients with COPD. Chest 1997; 112: 363-369.

11. Foster S, Thomas HM. Pulmonary rehabilitation in lung disease other than chronic obstructive pulmonary disease. Am Rev Respir Dis 1990; 141: 601-604.

12. Clark CJ. The role of physical training in asthma. In: Casaburi R, Petty TL, eds. The Principles and Practice of Pulmonary Rehabilitation. Philadelphia, PA, W.B. Saunders, 1993; pp. 424-438.

13. Emtner M, Herala M, Stalenheim G. High-intensity physical training in adults with asthma: a 10-week rehabilitation program. Chest 1996; 109: 323-330.

14. Cochrane L, Clark C. Benefits and problems of a physical training programme for asthmatic patients. Thorax 1990; 45: 345-351.

15. Cambach W, Chadwick-Straver RVM, Wagenaar RC, Van Keimpema ARJ, Kemper HCG. The effects of a commmunity-based pulmonary rehabilitation programme on exercise tolerance and quality of life: a randomized controlled trial. Eur Respir J 1997; 10: 104-113.

16. American Thoracic Society statement. Standards for the diagnosis and care of patients with chronic obstructive pulmonary disease. Am J Respir Crit Care Med 1995; 152: S77-S120.

17. Guidelines for the diagnosis and management of asthma. Bethesda, MD, Department of Health and Hu-man Services, DHHS Publication No 91-3042, 1991.

18. Maltais F, LeBlanc P, Jobin J, et al. Intensity of training and physiologic adaptation in patients with chronic obstructive pulmonary disease. Am J Respir Crit Care Med 1997; 155: 555-561.

19. Clark CJ, Cochrane L, Mackay E. Low intensity peripheral muscle conditioning improves exercise tolerance and breathlessness in COPD. Eur Respir J 1996; 9: 2590-2596.

20. Quanjer PH. Working Party on "Standardization of lung function test". Bull Eur Physiopathol Respir 1983; 19: Suppl. 5, 7-10.

21. Black L, Hyatt R. Maximal airway pressures: normal values and relationship to age and sex. Am Rev Respir Dis 1969; 99: 696-702.

22. Bruschi C, Cerveri I, Zoia MC, et al. Reference values of 
maximal respiratory mouth pressures: a population-based study. Am Rev Respir Dis 1992; 146: 790-793.

23. Borg GAV. Psychophysical basis of perceived exertion. Med Sci Sports Exerc 1992; 14: 377-381.

24. Butland RJA, Pang J, Gross ER, Woodcock AA, Geddes DM. Two, six and 12 minute walking tests in respiratory disease. Br Med J 1982; 284: 1607-1608.

25. Mahler D, Guyatt GH, Jones PW. Clinical measurement of dyspnea. In: Mahler D, ed. Dyspnea. New York, Marcel Dekker, 1998; pp. 149-198.

26. Ferrari K, Goti P, Misuri G, et al. Chronic exertional dyspnoea and respiratory muscle function in patients with chronic obstructive pulmonary disease. Lung 1997; 175: 311-319.

27. Jones PW, Quirk FH, Baveystock CM, Littlejohns P. A self-complete measure of health status for chronic airflow limitation. Am Rev Respir Dis 1992; 145: 1321-1327.

28. Carone M, Bertolotti G, Zotti AM, Donner CF, Jones PW. Validation of the St. George's respiratory questionnaire: Italian version. Eur Respir J 1997; 10: Suppl. 25, 457S.

29. Lacasse Y, Guyatt GH, Goldstein RS. The components of a respiratory rehabilitation program: a systematic overview. Chest 1997; 111: 1077-1088.

30. Varray AL, Mercier JG, Terral CM, Prefaut CG. Individualized aerobic and high intensity training for asthmatic children in an exercise readaptation program: is training always helpful for better adaptation to exercise? Chest 1991; 99: 579-586.

31. Strunk RC, Mascia AV, Lipkowitz MA, Wolf SI. Rehabilitation of a patient with asthma in the outpatient setting. J Allergy Clin Immunol 1991; 87: 601-611.

32. Weiner P, Azgad Y, Ganam R, Weiner M. Inspiratory muscle training in patients with bronchial asthma. Chest 1992; 102: 1357-1361.

33. Gosselink R, Troosters T, Decramer M. Exercise testing in COPD patients: the basic questions. Eur Respir J 1997; 10: 2884-2891.

34. McGavin CR, Artvinli M, Naoe H, McHardy GJR. Dyspnoea, disability and distance walked: comparison of estimates of exercise perforamce in respiratory disease. $\mathrm{Br}$ Med $J$ 1978; ii: 241-243.

35. Dyer CAE, Sinclair AJ. A hospital-based case-control study of quality of life in older asthmatics. Eur Respir $J$ 1997; 10: 337-341.

36. Tsukino M, Nishimura K, Ikeda A, Koyama H, Mishima M, Izumi T. Physiologic factors that determine the healthrelated quality of life in patients with COPD. Chest 1996; 110: 896-903.

37. Ketelaars CAJ, Schlosser MAG, Mostert R, Huyer AbuSaad H, Halfens RJG, Wouters EFM. Determinants of health-related quality of life in patients with chronic obstructive pulmonary disease. Thorax 1996; 51: 39-43.

38. Reardon J, Patel EC, ZuWallack RL. Improvement in quality of life is unrelated to improvement in exercise endurance after outpatient pulmonary rehabilitation. $J$ Cardiopulmon Rehabil 1993; 13: 51-54.

39. Osman LM, Godden DJ, Friend JAR, Legge JS, Douglas JG. Quality of life and hospital readmission in patients with chronic obstructive pulmonary disease. Thorax 1997; 52: 67-71.

40. Decramer M, Gosselink R, Trooster T, Verschueren M, Evers G. Muscle weakness is related to utilization of health care resources in COPD patients. Eur Respir $J$ 1997; 10: 417-423. 